\section{A Mobile Tutoring System for \\ Teaching Operators in Java (JO-Tutor)}

Preparation

Nehal El-Saied Ahamed

Demonstrator at El Shrouk Academy Computer

and Management Information System

Abstract:

This paper introduces a mobile tutoring system for teaching Java operators carried out in a mobile learning environment. For college students to overcome the difficulties they face. The application offers the subject of Java operators and administers routinely generated problems for the students to solve and righ their wrong Answers. This application generates tests to determine the student's understanding of the lesson introduced and the results obtained. A preliminary evaluation learn about was once carried out to look the impact of using the mobile tutoring system on the impar of the perom course in the instue or computer sciences and Intormalion technogy at EI Shrouk academy, Cairo, Egypt. The results confrmed a positive impact on the evaluators.

Keywords: Mobile Tutoring System, Java operators Mobile learning

Modern education is the main means of society to meet the challenges of the age, which are characterized by many variables and developments in various aspects, political, economic, social, and educationa and others. And became the real force in this age of those who possess science and technology, and from this has been the reform of education and development of the essentials focused on the state. This im posed on the education policy in Egypt to develop it per to join the revolution of inform sell to jon the revolu policy in Egypt to develop itmobile technology and employ them in the develop-
ment of the educational process.

In this regard, moden educational technologies, especially mobile technologies, play a major role in the development of educational processes. The use of

\section{Supervision}

\section{D.R. Maha Talaat}

Associate Professor Sadat Academy

for Management Sciences

ment in various fields such as medicine and engineering Space and others.

The main purpose of this research work is harnessing the proposed mobile tutoring system by developing and to be loaded via Internet to the mobiles of the students. So that, the teaching and tutoring proces is simplified for tutors by using mobiles. Also, the ubiquitous and networked, with enhanced capabilities for rich social interactions, context awareness and internet connectivity Such technologies can have a greatime me mere ouside of the classrom and his the learners

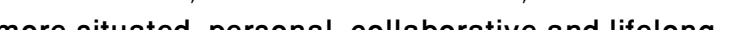
more situated, personal, collaborative and lirelong. The challenge wil be to discover how to use mobile technologies to transform learning into a seamless part of daily life to the point where it is not recognise as learning at all. Mobile tutoring system has the potential to deliver the significant advantages of Intelligent Tutorial System to a wider audience outside the traditional classrooms or computer labs. The use of smartphone those computers based instructiona have been moved off the desktop.

The proposed mobile tutoring system is an Android application that can help students who have their hardness and difficulties in Java Programming.

There are many Mobile Tutoring Systems (MTS) that were designed and developed for many areas such

In this study [ 1 ] is thereforee, developing mobile based in Ethiopiat can support distance learners learning process would be attractive and would be enhanced by the use of mobile applications.

Mobile technologies are becoming more embedded case. Both qualitative and quantitative case study re search methods have been applied to understand the existing distance learning context and identify problems, issues and requirements for developing the system. Interview and questionnaire used as a tool for data collection. The problems and requirements iden tified through qualitative and quantitative case study are used as a basis for developing contextualize and easily accessible mobile based tutorial system that can address the existing problems of delivering tutorial services and meet system requirements identified by learners and educators.

In this study [2] aimed to present mobile application to explore how student learning behaviour and well-being changed with a transition in learning design from the traditional lecture-based approach to a flippedclassroom approach. Students were recruited during three eight-week Child and Adolescent Health blocks of a four-year graduate-entry medical program.

In this study [3] they developed Cyrus which is a mobilis a mobile application that suppors a large type of query classes, surficient for an entry level database class. Cyrus is also applica tion independent, allows test da-

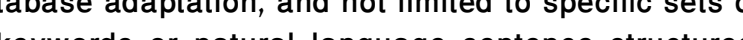
keywords or natural language sentence structures. in is cooperalive error reporting is more intulive, and cos based mobile platerm is also more accessible compared to most contemporary mobile and voice enabled systems. But in the proposed system, there is weaker ability to map all division and aggregat queries; the progress Cyrus embodies is nonetheless intellectually satisfying.

searcher comments on Most previous reviews of mobile technologies for learning categories examples of use according to curriculum area. we believe that the benefits of mobile technologies for learning encompass more than just what an individual can do with a device, and that there is thus a need for a wider review of new and emerging practices and how these relate to theories and paradigms previously established for the use of computers in education

In my observation many researchers proposed new paradigms of Mobile Tutoring System (MTS) for teaching languages, mathematics, programming and etc. with Mobile learning techniques for adaptive learning with Mobile And the Al system in particular uses machin learning and adaptive Hypermedia to implement MTS which adapts to the requirements of learners and Which ads the tutoring Mobile Application for teaching operators in

\section{Java (JO Tutor).}

The research problem addressed is that mobile tutoring system is not supported up till now in the Egypthan higher education institutions. Especially, the higher institute of computing and information technology in El Shrouk Academy. The academic administration of any Egyptian higher education institute did not have any information on the level of studen interest in participating in mobile learning.

Research in this area thereforee is of interest to higher education and technical professionals involved in supporting various delivery methods and may possibly be essential at some period now or in the future that could not iety has observed an explosion in mobile The above research problem is to be summarized in the following sub problems:

) Limited accessibility in mobile tutoring systems in higher education.

2) Small percentage of higher education students who use mobile tutoring system

3) The purpose of the instructions used during programming (Java programming) Students could not be easily understood.

4. Research questions

We can conclude from this previous presentation that a number of questions that defines the thesis problem as follow:

Q1- How important is the use of mobile learning Application in general and Mobile tutoring system (MTS) in class, especially in the development of the educational process?

extent of understanding of the scientific material of programming (Java operators especially)?

Q3- How to design, implement and measure performance of the proposed mobile tutoring system? Q4- What is the impact of the proposed mobile application on the educational community in universitie in Egypt?

Q5- What is the extent of the society's influence on the education from terms such as (demographics of population in different governorates at different universities of Egypt)?

5. Research objectives

1) Building a proposed mobile tutoring system for teaching Java operators in higher education.

2) Determining the chracteristics of the system most in Determining the characteristics of the system mos and experts in this field. 
3) Updating the system according to the proposals proposed by academics and experts in the field. For example, the propositions of the third and fourth hy pothesis.

4) Generating number of questions, Exercise, problems automatically, thereby providing as much practice with problem solving as the student needs.

5) Building familiar interactive interfaces like mobile screens.

6) Developing a system that is dynamically adapted at run time to the student's individual Progress in higher education.

7) Establishing flexible learning environment that can be accessed

6. Research importance

1) Provide the system that suites the environment we have in Egypt, user friendly and cost effective.

2) Development of learning tools and technology to be compatible with modern technology developments and this has been taken into account in the proposed system.

3) Learners could be able to learn at their own pace anywhere using any device to be self-educated. 4) Provides an automatic and intellectual teaching methodology.

5) Provide curriculum content suggesting unit (operators in the language of Java) as an important key issues in the programming language Java.

6) The importance of developing educational Mobile Application automated service using mobile learning technology have been clarified because our mobile application has shown positive results.

7. Research Methodo

7. Research Methodology od, case study method, questionnaire method and exerimental method.

Research hypotheses

The research hypotheses were formulated as follows: 1) There are statistically significant differences be tween the average scores of the sample in the exten of understanding of the scientific material of programming (Java operators especially). The pretest befor and after the use of the proposed Mobile tutoring sysem to teach the "Java operators" unit for the benefit of the post application at the level of $(0.01)$

2) There are statistically significant differences between the average scores of the sample in the design implementation and measured performance of the proposed mobile application. The post-test before and after the use of the proposed Mobile tutoring system to teach the "Java operators" unit for the benefit of the e level of $(0.01)$

There are statistically significant differences beThen the average scores of the sample in the impact twe community in universities in Egypt. The post-test becore and afer the use of the proposed Moble tutorng tore and atter the use or the proposed Mobile tutoring system to teach the "Java operators" unit for the benefit of the post application at the level of $(0.01)$

4) There are statistically significant difference between the average scores of the sample in the extent of the society's influence on the education from terms such as (demographics of population in different governorates at different universities of Egypt). The post-test before and after the use of the proposed Mobile tutoring system to teach the "Java operators" unit for the benefit of the post application at the level of $(0.01)$

9. Research sample

The lecturers and their students who Enrolled in Computer Science III (Advanced Java) during the fall semester of 2017/2018 in the institute of compute sciences and Information technology at El Shrouk Academy, Cairo, Egypt. A group of 25 lecturers and 200 students participated in the evaluation of the inelligent tutoring system for teaching Java operators. 10. Research Tools

1) Preparation of a questionnaire to survey the opinion Preparion ing system for teaching operators in Java (Prepared by the researcher).

The teaching content of the unit operators in Java language.

3) Create a Mobile tutoring system to teach the unit operators in Java language.

Pre and post-test to measure the level of achievement and skills of students in the research sample (Prepared by the researchen.

11. Research procedures

1) Comprehensive analytical study of research and literature on the subject and current research variables. 2) Preparing a survey on the learning of mobile teaching and its applications and the difficult materials that university students need to understand through mobile tutoring system.

3) Prepare and design research tools and make sure they are reliable and stable.

4) Building a mobile tutoring system for teaching operators in Java language for university students.

5) Conduct an exploratory study on the mobile tutor-

ing system before practical application.

6) Selection of the research sample and application on it
7) Apply research tools to a search sample (pretest 8) Conducting the experiment, applying the mobile in telligent tutoring system and $t$ research sample (post-test).

9) Data collection, processing and statistical analysis to get the results and interpretation.

10) Extracting results.

11) Formulation of recommendations and suggestions.

12. Research Results

1) There are statistically significant differences be ween the average scores of the sample in the exten of understanding of the scientific material of program ming (Java operators especially). The pretest before and after the use of the proposed Mobile tutoring system to teach the "Java operators" unit for the benefit of the post application at the level of $(0.01$

2) There are statistically significant differences between the average scores of the sample in the design, implementation and measured performance of proposed mobil application. The post-test befor the fer the use of the prosed Mobile tutoring system after the use or ap propon. The post-lest betore and to teach the "Java operators" unit for the benefit of the

The salsicaly significant differences between the average scores or the sample in the impact com proposed in universiles in Egypt the post-test becommunity in universities in Egypt the post-test before and after the use of the proposed Mobile tutoring system to teach the "Java operators" unit for the b efit of the post application at the level of $(0.01)$.

4) There are statistically significant differences be tween the average scores of the sample in the extent of the society's influence on the education from terms such as (demographics of population in different gov ernorates at different universities of Egypt), the posttest before and after the use of the proposed Mobile tutoring system to teach the "Java operators" unit for the benefit of the post application at the level of $(0.01)$. 5) Demonstrate the effectiveness of Mobile Tutoring system in the development of the educational process and solve the problems of students, especially in programming materials of a difficult and complex nature. 6) The evaluation of the Java Operators - Tutor showed a positive impact on the evaluators (Lecturers and students)

13. Research recommendations and suggestions.

1) Recommend that the role of mobile devices which an play to use mobi mas those students find difficult to study.

كمبيونت العدد 23 (ديسمبر 2019) search to researchers towards the design, produc tion and measurement of the effectiveness of mobile learning with its various applications and technologies in the educationalprocess and materials in varous university and school stages, especially in relation to mobile tutoring systems.

3) It is recommended to introduce modifications and add new possibilities to the student module, whic is the main part of the structure of mobile tutoring system, where the student represents the interaction with the mobile tutoring system that suits his individual needs and solve and facilitate the difficulties and problems facing the student through mobile tutoring systems.

4) Recommend that similar Mobile Application for other courses to be implemented.

Recommend using Java operators-Tutor for Computer Science III (advanced Java) as a supportive too 6) Suggesting conducting similar studies for this study deals with other subjects that are difficult to undertand and complex for students at all levels of education and not only university education as stated in the rearch.

14. Research terminologies

1- Mobile Learning

Mobile learning is "learning across multiple conexts, through social and content interactions, using ersonal electronic devices" [4]. A form of distance education, $\mathrm{m}$-learners use mobile device educationa echnology at their convenient time. [5] M-learning technologies include handheld computers, MP3 players, notebooks, mobile phones and tablets. M-learning focuses on the mobility of the learner, interacting with portable technologies. Using mobile tools for creating learning aids and materials becomes an important part of informal learning. [6]M-learning is convenient in that it is accessible from virtually anywhere. Sharing is almost instantaneous among everyone us ing the same content, which leads to the reception of instant feedback and tips. This highly active process ince exam scores from the fiftth to the seventieth percentile, and cut the dropout ate in technical fields by 22 percent. [7] M-learning also brings strong portability by replacing books and notes with small devices, filled with tailored learning contents. M-learning has the added benefit of being cost effective, as the price of digital content on tablets is falling sharply compared to the traditional media (books, CD and DVD, etc.).

The delivery of tutoring systems on mobile devices

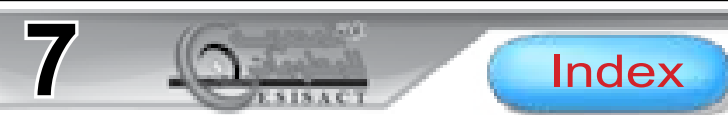

كمبيونت العدد 23 (ديسمبر 2019)

Index 
of intelligent tutoring systems to a wider audience of learners. Despite the fact that nearly all schools provide Internet and computer access to students, a deeper examination reveals that the presence of technology does not equate to effective use of the technology. Perhaps surprisingly, in a recent survey, only one-third of survey teachers indicate feeling prepared to use computers and the Internet for instruction [8]. Another factor hindering use is the student-to-computer ratio in schools: in 2005, no school reported having one computer for each child with the lowest computer to student ratio being approximately 3-to-1. Unfortunately, schools with greater numbers of minority students enrolled reported a higher number of students per computer [8]. The low cost of mobile and handheld devices has the potential to deliver a one-to-one computing solution to the education community [9].

\section{3- Java (programming language)}

Java is a general-purpose computer-programming language that is concurrent, class-based, object-oriented, [10]and specifically designed to have as few implementation dependencies as possible. It is intended to let application developers "write once, run anywhere" (WORA), meaning that compiled Java code can run on all platforms that support Java without the need for recompilation. [11] Java applications are typically compiled to bytecode that can run on any Java virtual machine (JVM) regardless of computer architecture. As of 2016, Java is one of the most popular programming languages in use, [12] particularly for client-server web applications, with a reported 9 million developers. [12] Java was originally developed by James Gosling at Sun Microsystems (which has since been acquired by Oracle Corporation) and released in 1995 as a core component of Sun Microsystems' Java platform. The language derives much of its original features from SmallTalk, with a syntax similar to $C$ and $C_{++}$, but it has fewer low-level facilities than either of them.

\section{References}

[1] ALI, MOHAMMED. , "MOBILE BASED TUTORING SYSTEM IN DISTANCE LEARNING: THE CASE OF ST. MARY'S UNIVERSITY.," Diss. St. Mary's University, 2018. [2] Y. M. A. M. B. J. P. A. \&. S. K. M. Zhao, " Exploring how medical students learn during clinical rotations: a pilot study with a mobile application.," Health and Technology, , pp. 1-11., (2019).

[3] Godinez, J. E., \& Jamil, H. M. , " Meet cyrus: the query by voice mobile assistant for the tutoring and formative assessment of SQL learners," In Proceedings of the $34^{\text {th }}$
ACM/SIGAPP Symposium on Applied Computing, pp. (pp. 2461-2468), (2019, April).

[4] Crompton, H. . In Z. L. Berge \& L. Y. Muilenburg (Eds.), , " "A historical overview of mobile learning: Toward learner-centered education".Handbook of mobile learning," Florence, KY: Routledge., p. (pp. 3-14)., (2013). [5] M. L. Crescente and D. Lee, "'Critical issues of $m$ learning: design models, adoption processes, and future trends".," Journal of the Chinese Institute of Industrial Engineers, p. 28 (2): 111-123, (March 2011)..

[6] Trentin G. \& Repetto M. (Eds) ., " Using Network and Mobile Technology to Bridge Formal and Informal Learning,", Woodhead/Chandos Publishing Limited,Cambridge, UK,, (2013).

[7] Saylor, Michael, "The Mobile Wave: How Mobile Intelligence Will Change Everything.," Perseus Books/ Vanguard Press., p. p. 176., (2012). .

[8] J. Wells and L. Lewis, , "Internet Access in U.S. Public Schools and Classrooms: 1994-2005,", "National Center for Education Statistics, Washington, D. C. , p. 2006.

[9] C. Norris and E. Soloway, , "Envisioning The Handheld-Centri Classroom,", " Journal of Educational Computing Research, , Vols. vol. 30, , pp. pp. 281-294,, 2004. [10] Gosling, James; Joy, Bill; Steele, Guy; Bracha, Gilad; Buckley, Alex ," "Design goals of the Java programming language,"," Java language specification, , January 1, 1999 Archived from the original Retrieved January 14, 2013.(online).

[11] McMillan, Robert, "Java is on the wane, at least according to one outfit that keeps on eye on the everchanging world of computer programming languages.," 1 August 2013, Archived from the original on February 15, 2017. Retrieved March 8, 2017. .

[12] "Java takes on the internet of things," Java one, review 2013, Archived from the original on April 19, 2016. Retrieved June 19, 2016.

[13] Gosling, James; Joy, Bill; Steele, Guy; Bracha, Gilad; Buckley, Alex , Java language specification, 2014.

[14] "Design goals of the Java programming language," January 1, 1999 Archived from the original on January 23, 2013. Retrieved January 14, 2013.. [Online]. 